\title{
DEL EXCENTRISMO FORMALISTA AL PRINCIPIO DEL MONTAJE
}

\author{
Vicente Sánchez-Biosca
}

(Universidad de Valencia)

FORMALISMO Y PRÁCTICA DE VANGUARDIA

Hace ya algún tiempo, Pozuelo (1988a y b) evaluó con precisión la importancia para la teoría literaria de la poética desautomatizadora promovida por los formalistas rusos, al tiempo que puso de manifiesto hasta qué punto la oposición entre el lenguaje poético y el lenguaje normal había ya estado en la base de la concepción grecolatina y su tradición, sólo rota por la teoría romántica que buscaba la literariedad en esencias simbólicas ${ }^{1}$. Pozuelo sostenía que la contribución fundamental de la OPOIAZ consistió en la rentabilidad del término teórico desautomatización oponiéndolo al de mero desvío (Pozuelo, 1988:34). Esta consideración de conjunto puede ponerse en relación con el fenómeno que se ha dado en llamar 'crisis de la literariedad'. Con esta

1 La importancia del formalismo para la teoría literaria había sido ya objeto del texto clave de García Berrio (1973). 
expresión se levanta acta de la decadencia producida desde finales de los años sesenta del paradigma formalista de cuño inmanentista en beneficio de una multiplicidad de paradigmas que Darío Villanueva, recogiendo el término de Paul K. Feyerabend, ha denominado proliferación (Villanueva, 1991:204).

La convergencia de estos dos hechos nos permite inscribir en la historia con mayor precisión la aportación formalista, dibujándola bajo sus condiciones específicas de formación. En otras palabras, la justeza de la consideración de Pozuelo no debería hacernos perder de vista el marco vanguardista, de intervención poética $y$, por ende, determinado históricamente que se inspiraron las primera teoría y práctica de los formalistas rusos, pues ambas facetas son en este caso difíciles de discernir. Perdido el valor de modelo incuestionable del formalismo, parece necesario, no su abandono, sino su percepción en el contexto adecuado que lo vio surgir. Podría, así, afirmarse que la sensibilidad fragmentarizante, disruptiva y excéntrica que da cobijo a sus primeros postulados es indisociable del clima de la vanguardia de las primeras décadas de siglo y resulta, a la postre, incomprensible al margen del mismo. Abundantes son las referencias que avalan esta constatación. Por sólo citar alguna de ellas, Jakobson, en sus conversaciones con Krystina Pomorska, se remonta a un período muy temprano, anterior a la aparición de la OPOIAZ y relata el acicate teórico que supuso para él la indagación vanguardista, tanto literaria como plástica: V. Jlébnikov y Kruchényj por sus creaciones y disecciones de palabras, pero también las investigaciones formales de Malévich en pintura. La declaración de Jakobson disipa toda duda: «Por mi parte, yo me esforzaba obstinadamente en mis textos y en mis meditaciones teóricas en alejarme de las palabras y de su significación, en concentrarme en los componentes elementales de la palabra, en los sonidos del lenguaje en cuanto tales, despojados tanto de toda analogía dudosa con la música como de su confusión con la escritura» (Jakobson, 1981:17). Por su parte, Sklovski apelaba como sanción de su concepto de ostranenie a idénticos experimentos poéticos, aun cuando su corpus de aplicación se apoyara preferentemente en autores clásicos: «Finalmente somos testigos de la aparición de una fuerte tendencia que trata de crear una lengua específicamente poética; a la cabeza de esta escuela se ha colocado, como se sabe, Velemir Jlebnikov» (Sklovski, 1970: 70). Y, por no proliferar en citas innecesarias, el propio Viktor Erlich dice al remontarse a la génesis del Círculo Lingüístico de Moscú en 1915 y la posterior OPOJAZ: «Fascinación por los descubrimientos de la vanguardia literaria e impaciencia por los procedimientos caducos de la ciencia 
literaria: éstos fueron los síntomas principales de aquel fermento intelectual que en la segunda década de este siglo cristalizó en un movimiento organizado» (Erlich, 1974:89). Localizando este período germinal comprendido entre 1916 y 1921, Eichenbaum (1970:55) lo considera marcado por las consignas y fines propagandísticos y lo juzga, en todo caso, anterior al de constitución de una ciencia de la literatura (surgimiento de las nociones de construcción, sistema, historia literaria, etc) por la que los formalistas muestran su preocupación poco tiempo después.

No es pretensión de estas páginas interrogar una vez más la contribución formalista a la teoría literaria, sino más bien subrayar su condición de síntoma de la modernidad artística. En otras palabras, en lugar de promover una lectura teleológica de los conceptos iniciales del formalismo juzgándolos primerizos o fundadores de las ideas más elaboradas de construcción, historia literaria, sistema, etc que supondrían la contribución decisiva de la escuela en cuestión ${ }^{2}$, proponemos ver en ellos el sello de algo que fractura toda la primera vanguardia, a saber: una manifestación excéntrica y disruptiva que atraviesa todas las artes y buena parte de las teorizaciones, poéticas y manifiestos del período y que desearíamos denominar la irrupción del principio de montaje en la modernidad.. Ahora bien, suponer lo anterior nos obligará, en un segundo momento, a disociar la ostranenie del marco literario que la ve nacer para inscribirla en el orden estético general, subrayando su operatividad en otras artes. Por último, podrá advertirse la pertinencia de este planteamiento para cerrar el bucle con el estudio del cine, espacio discursivo en el cual el mecanismo técnico del montaje sufre una sorprendente literalización.

\section{LA «OSTRANENIE» COMO MONTAJE}

Sea el celebérrimo concepto de ostranenie o extrañamiento que Viktor Sklovski acuñara en 1917. Este, identificado con la imagen poética,

2 Lectura causalista que no tiene por qué ser inadecuada y cuyo primer artífice fue el mismo Eichenbaum con su texto de 1925 «La teoría del método formal». Para este autor, este concepto abrió el camino para un estudio de la forma; por su parte, la idea jakobsoniana de «literaturnost» o literariedad, mucho más elaborada, arranca de un desarrollo y complejización de la «ostranenie». Pero el propio Tinianov escribiría en 1923 su texto «La noción de construcción» en el que insiste sobre el aspecto integrativo. Lejos parece quedar el aspecto rupturista al que deseamos consagrar este escrito. 
consiste - dice el autor- en arrancar el objeto de su contexto habitual y colocarlo en otro inesperado. El resultado de esta operación devuelve al conjunto - y no sólo al elemento desplazado ${ }^{3}$ - la perceptibilidad que su uso estereotipado le había cercenado y, en consecuencia, los hechos se presentan a la percepción como una 'visión' (como si fueran vistos por primera vez), en lugar de hacerlo como reconocimiento. Esto es de sobra conocido y no merecería ser citado de nuevo si no fuera de manera táctica, es decir, para avanzar algo más en nuestras intenciones. Consideramos, pues, esta referencia como mero punto de partida y deseamos rescatar dos elementos en la definición: el efecto de violencia perceptiva que impone al lector y el carácter centrífugo que la ostranenie introduce respecto a la estructura compacta - transparente- del texto. En un ensayo de 1923 titulado «Literatura y cine», el mismo Sklovski nos ofrece una bella descripción del miserable panorama del lenguaje contra el que pretende reaccionar la ostranenie, al tiempo que anuncia la dimensión extraliteraria del procedimiento:

\begin{abstract}
"Vivimos en un mundo cerrado y mezquino. No sentimos el mundo en el que vivimos como no sentimos la indumentaria que llevamos puesta. Volamos a través del mundo como los héroes de Julio Verne 'a través del espacio cósmico en el vientre de un cohete'. Pero nuestro cohete no tiene ventanas.

«Los pitagóricos afirmaban que no oímos la música de las esferas porque suena incesantemente. Así, quienes viven en las orillas del mar no oyen el rumor de las olas, pero nosotros ni siquiera oímos las palabras que pronunciamos. Hablamos un miserable lenguaje de palabras no dichas a fondo. Nos miramos a la cara pero no nos vemos» (Sklovski 1971:107).
\end{abstract}

Por consiguiente, el resultado del extrañamiento es un enriquecimiento de la forma, de aquello justamente que pasa desapercibido en el uso habitual y éste es el comportamiento propio del discurso poético. Ahora bien, Sklovski añade que el uso del extrañamiento no es en absoluto patrimonio de la vanguardia, sino que ya se encuentra en la literatura clásica rusa, con Tolstoi y Pushkin a la cabeza. ¿Por qué, entonces, haber esperado hasta este momento para advertir su importancia? ${ }^{4}$ Es aquí donde nos agradaría inscribir nuestra intervención: el concepto de extrañamiento y sus derivaciones teóricas más consecuen-

3 El mismo Tinianov señalaba en su texto de 1924 «El ritmo como factor constructivo del verso" (1975: 26) que el factor evidenciado deforma también los subordinados.

4 Recuérdese que Pozuelo (1988) ya señaló con detalle el valor de la desviación en las poéticas clásicas. 
tes adquieren sólo su pleno rendimiento observados a la luz de una poética que postula la violencia perceptiva, el shock emocional, y que concibe el texto como el desmantelamiento de una estructura compacta. En la teoría y en la práctica, el sujeto de la enunciación que la vanguardia propone opera un extraño despedazamiento de su texto. $Y$ es que la vanguardia, en cuanto fractura de la modernidad artística, constituye el impulso que los formalistas precisaban para descubrir procedimientos excéntricos que no son específicamente vanguardistas, pero que sólo al calor de su actitud excéntrica pueden ser reconocidos en otros períodos y otras obras. Valdría la pena detenerse en un ejemplo, aunque de forzosa brevedad, para mejor exponer esta idea.

Sabemos que el fragmentarismo y ciertas formas de 'collage' fueron moneda corriente en el arte medieval; sorprende, con todo, su práctica desaparición durante siglos hasta el período de irrupción de las vanguardias, donde se impusieron con inusitada contundencia. La tentación de asimilar estas dos fórmulas -medieval y vanguardista- encerraría, sin embargo, un craso error de cálculo, pues no cabe duda de que, más allá de su semejanza formal, la significación de ambas manifestaciones es radicalmente distinta y, a fin de cuentas, su similitud resulta incomprensible si no se toma en consideración el esfuerzo del arte renacentista por construir un espacio compacto, homogéneo y habitable a partir de la llamada perspectiva artificialis. En efecto, ésta instaura con ayuda de la geometría euclidiana y la centralidad del punto de vista, un espacio antropomorfo coherente que responde al nuevo papel de la ciencia en el universo renacentista y a la función central asignada al ojo en la percepción del mundo y que destituye el espacio de agregados medieval. La descomposición de este espacio plástico hacia finales del XIX a partir de los postimpresionistas de la Escuela de París (Francastel, 1975) y su radical disolución con los primeros 'papiers-collés' cubistas están unidos a la crisis de un modelo de sujeto racional ordenador, así como de paradigma científico. Nos excusamos por el carácter sucinto de esta explicación, que sin duda peca de elíptica, pero nos sirve para llamar la atención sobre las insuficiencias de una interpretación meramente formalista de determinados rasgos significantes al margen de su contexto de enunciación. Con todo, este pequeño desvío nos ha permitido de paso situar la 'ostranenie' fuera de un marco estrictamente literario. Parece, pues, pertinente covenir en la extensión que propone Gillo Dorfles del término en cuestión a «todos aquellos casos en que se presenta un fenómeno de escisión, de disyunción entre un fragmento y el texto, entre una obra y su contexto, entre una palabra y su colocación normal, como consecuencia de la 
cual dichos elementos son susceptibles de una fruición más profunda y 'especializada'» (Dorfles, 1984:98).

Regresemos de nuevo al contexto vanguardista en que se fraguó la noción que nos ocupa. Si de este procedimiento retenemos su perceptibilidad formal excéntrica, no sólo podemos reconocer en él un eco de los experimentos de 'zatrudnânnaja forma' (forma deliberadamente obstruida), propuesta por Krucheny y Kamenski o el proyecto de fundir libremente palabras eslavas presentado por Jlebnikov, sino también -y esto es capital para nuestro razonamiento- estamos autorizados a hallar un mismo fermento que nos conduce a la propuesta de asintactismo en la composición poética defendida por Marinetti y los futuristas italianos, así como la irrupción del azar en los métodos de composición de poemas dadaístas propuestos por Tristan Tzara o incluso la emergencia del lapsus en la escritura automática superrealista. Veámoslo. El futurismo concibe la ruptura con la sintaxis, tal y como figura en el «Manifiesto técnico de la literatura futurista» de 11 de mayo de 1912, como una forma de construir redes estrechas de imágenes o analogías que tenderán a captar todo lo que hay de más huidizo en la materia. La destrucción del yo, de la lógica oracional, de los epítetos, la nuclearización de la lengua llevan a postular a Marinetti sus célebres 'palabras en libertad' (Marinetti et al., 1973:77-84). Nada hay de casual en que los autores del manifiesto pongan en relación esta absoluta libertad de las palabras con la idea de hombre mecánico de partes intercambiables o la defensa de una poética de la sorpresa que se plasmaría en sus 'serate futuriste'. Otro tanto cabría afirmar del provocativo sistema compositivo de poemas dadaístas propuesto por Tristan Tzara (1972) en el cual se trata de unir palabras y barajarlas al azar con total gratuidad para obtener un resultado totalmente aleatorio. Igualmente, la producción de textos automáticos de André Breton en 1924 (1975) obedece a una técnica de montaje en tanto en cuanto su cometido es unir lo heterogéneo haciéndolo chocar en la percepción del lector. Estamos, a fin de cuentas, ante una técnica de shock. Ahora bien, una reflexión algo más cuidadosa nos revelará que estas dos últimas manifestaciones - dadaísmo y superrealismo- son rabiosamente opuestas, pues, a diferencia de Dadá, la poética bretoniana parte del azar para acabar negándole todo estatuto. En realidad, si Breton postula la existencia del azar objetivo es porque cree, al igual que Freud, en la causalidad psíquica y si es cierto que el azar está determinado por el inconsciente, entonces no existe sino la necesidad. La oposición que ahora presentimos entre dadaísmo y superrealismo prefigura otra que se nos aclarará más adelante entre montaje y construcción. 
Lo expuesto nos conduce a una conclusión casi inevitable: en todas las concepciones mencionadas, la parte se autonomiza respecto al todo y la estructura orgánica se quiebra, desvelando el texto como una mera composición de agregados. Además, esta técnica establece con el espectador una relación de violencia cuya mejor expresión es el shock emotivo. No se trata - claro está- de ignorar los matices que distinguen entre sí todos estos procedimientos ni tampoco de minimizar los desajustes cronológicos existentes entre las diversas posturas que hemos traído a colación, sino más bien de reconocer en todos ellos la manifestación de una misma categoría, a saber, la de montaje, en la cual se acentúa la disgregación de los significantes en lugar de hallarse éstos unificados en una estructura compacta y centrípeta. Diríamos que la enunciación se muestra incapaz de c oser la heterogeneidad de las partes borrando sus desajustes. La pérdida de cualquier resto de ilusión referencial se encuentra indisolublemente ligada a este destino. Triunfa, por tanto, el principio de desmembramiento en detrimento de una concepción organicista del texto ${ }^{5}$.

Añadamos a lo anterior, para mayor abundamiento, algunas manifestaciones extraliterarias todavía más explícitas respecto a la concepción de un espacio de agregados: el 'collage' pictórico, comenzando por los 'papiers-collés' de Braque y Picasso y atravesando futurismo, dadaísmo y superrealismo, la generalización del fotomontaje en el dadaísmo berlinés, de Raoul Haussmann a Hannah Höch, pasando por John Heartfield o Kurt Schwitters ${ }^{6}$, la cartelística de propaganda política durante la Alemania de Weimar, la concepción de Mejerhold del teatro como amalgama (en cuyo espectáculo se incluyen pequeñas proyecciones cinematográficas), el resurgir de espectáculos de atracciones como el circo, la feria y las diversiones populares y excéntricas (el cinematógrafo entre ellas), de los que se hicieron eco tanto el teatro de Brecht como el de Eisenstein ${ }^{7}$... Llegaremos fácilmente a la conclusión de que también en estos fenómenos y prácticas artísticas o pseudoartísticas un mismo procedimiento está en juego: el montaje.

5 La misma metáfora organicista es elocuente de cuanto decimos: concibe la obra de arte como un organismo vivo y postula para ella un sentido biológico y funcional de sus componentes.

6 Fueron George Grosz y Heartfield quienes usaron en alemán el neologismo MONTIEREN para dar cuenta de este experimento.

7 Las insistentes referencias al deporte en la poética brechtiana y las que remiten al circo en el montaje de las atracciones eisensteiniano son elocuentes de hasta qué punto estos fermentos penetraron incluso el espectáculo teatral culto y revolucionario. La teoría de Benjamín sobre el teatro épico brechtiano se organiza sistemáticamente sobre los signos del montaje, a saber: interrupción y shock (Benjamin, 1975). 
Resumiendo lo expuesto, podríamos concluir lo siguiente: en todos los ejemplos señalados la enunciación exhibe el principio de montaje que sirvió para la composición, pues el extrañamiento del fragmento, del fonema o de cualquier otro segmento textual respecto al previsible sentido lógico y verosímil del texto introduce una percepción intensificada de todos y cada uno de los elementos que componen la obra en lugar de propiciar su percepción en cuanto totalidad borrando consiguientemente la autonomía de las partes. Por demás, el lector está llamado a certificar el régimen de extrañamiento, pues es él mismo quien - permítasenos el juego de palabras — ha sido extrañado con violencia del y por el texto.

\section{EL MONTAJE COMO CATEGORÍA ESTÉTICA}

La ostranenie, como concepto teórico y actitud, se convierte, así, en un síntoma de un principio estético más general, al tiempo que un instrumento de doble valor: teórico, sin duda, pero también combativo, heredero o, cuando menos, coordinado con otras manifestaciones del mismo principio. Podría afirmarse que la teoría formalista rusa vive las mismas etapas y progresión de las vanguardias: de una tendencia centrífuga del texto que propone, descubre y teoriza el shock perceptivo sobre el lector o espectador a una dimensión constructiva, estructural que, por añadidura, atiende cada vez en mayor medida la dimensión diacrónica de los textos. Por supuesto, lo que aquí desplegamos en un sentido temporal lógico puede leerse igualmente como contradicción, es decir, como momentánea superposición o encabalgamiento entre distintas fases. En suma, la ostranenie abre a la lectura y torna explícito el proceso de fabricación técnica del texto. Por decirlo con las palabras de Bürger (1987:137): «El montaje supone la fragmentación de la realidad y describe la fase de la constitución de la obra».

Nos hallamos, por consiguiente, ante la irrupción de un principio el de montaje - que, según Adorno (1980:81) se opone al principio organicista de la obra de arte. El razonamiento de Adorno arranca del enfrentamiento entre composición y construcción. Responde la primera a una concepción organicista de la obra de arte, en la cual la parte y el todo mantienen una relación dialéctica, mientras el segundo produce una síntesis a costa de los momentos cualitativos y del sujeto que parece desaparecer (caso ejemplar de esto último sería la obra de Piet 
Mondrian). La construcción - prosigue Adorno- saca al arte de su situación nominalista, pero también implica una síntesis, para cuyo triunfo ha de imponerse tiránicamente a todos los componentes que, debido a esta violencia, nunca estarán de acuerdo con la unidad que se les impone. A pesar de todo, Adorno parece matizar una oposición ulterior entre montaje y construcción, que resulta especialmente pertinente para nuestros fines. Si una primera fase de las vanguardias, especialmente plásticas, operaba el desmembramiento de las estructuras, dando autonomía a los fragmentos, los cuales se emancipaban de la totalidad (montaje), pronto se impondría (de nuevo en contradicción lógica con lo anterior) una enunciación tiránica - principio de construcción- cuyo efecto consistiría en la reintegración, en lugar de insistir en la descomposición, la amalgama, la perceptibilidad de las fisuras que abren la obra de arte, es decir, la autonomía de sus componentes. La oposición entre el 'collage' cubista y el constructivismo de Malévich, por ejemplo, daría cuenta, de un modo harto ilustrativo, de este conflicto entre montaje y construcción. En nuestra opinión, se trata de concebir - tomando en este momento cierta distancia respecto a Adorno- que el montaje es este principio textual que, expreso o no, regula la discrepancia entre los significantes que constituyen el texto artístico y cuya expresión privilegiada es el texto desplegado y de montaje visible propio de la fase analítica de la vanguardia, en palabras de Menna (1977) ${ }^{8}$. Ahora bien, si constatamos que los significantes de un texto son por definición heterogéneos entre sí, concluiremos que lo que el montaje - en cuanto sujeto de la enunciación del texto moderno- hace es abrir la brecha de la heterogeneidad significante, es decir, descubrir lo que antes había estado encubierto o recubierto por la sutura y el efecto de transparencia del texto clásico.

En suma, disgregación perceptible en la estructura, shock en relación con el espectador o lector e inspiración en la producción de bienes materiales que el arte imita son, a nuestro juicio, los rasgos decisivos de este efecto de montaje que irrumpe en la escena artística a comienzos del siglo Xx. Ni que decir tiene que el origen de todos estos fenómenos se fue larvando durante el siglo XIX, como demuestra con belleza y extrema lucidez la famosa y inconclusa obra de los pasajes, de Benjamin (1982). Pues bien, justo es reconocer estos tres rasgos no coinciden forzosamente en todas las obras, pero que pueden ser reconocidos como característicos de una misma época. El hecho de que la

8 Con alguna excepción notable como es el caso del expresionismo (Sánchez-Biosca 1987). 
noción de montaje tenga su origen en la ingeniería no es casual, como tampoco que su devenir lo conduzca a una máquina, a saber: el cinematógrafo. Y en este último caso no se tratará ya de esa máquina estilizada que fue el automóvil de carreras de Marinetti, mero emblema de la ruptura con una tradición estática y extática en la que el arte decadente se regocijaba, sino lisa y llanamente una máquina de discurso. En resumen, el montaje se nos aparece como la herencia de la modernidad depositada sobre un objeto a un mismo tiempo técnico y discursivo como es el cinematógrafo. Que la vanguardia cinematográfica tardara tanto tiempo en advertir la fecundidad histórica de este encuentro abre un fascinante campo de estudio que la estética tan sólo ha esbozado hasta el momento?.

\section{EL ENCUENTRO DE FORMALISTAS Y EXCÉNTRICOS}

Fue Viktor Shklovski quien subrayó en 1928 el paralelismo entre la actitud excéntrica del grupo teatral y cinematográfico conocido como FEKS (Fábrica del Actor Excéntrico) y la teoría que Serguei M. Eisenstein formuló en el seno del Proletkult teatral como montaje de atracciones. Lo curioso del asunto es que Shklovki traza el vínculo a partir de su propia concepción de la ostranenie: «Puede que el excentrismo desplazara la atención de la construcción al material. De todas formas, la teoría del montaje de atracciones está en conexión con el excentrismo. Este último se funda en la elección de los momentos más significativos y en una nueva correlación, no automática, entre ellos. El excentrismo es la lucha contra la rutina, el rechazo de la percepción y de la reproducción tradicional de la vida» (Sklovski, 1978:86) .

En efecto, Sklovski advierte la existencia de un principio común en concepciones heterogéneas procedentes de campos artísticos distintos: la ostranenie se convierte, así, en un término teórico y operativo. Por su parte, el excentrismo de la FEKS se aplica al teatro y, con posterio-

9 Es un hecho que la vanguardia saluda al cine con entusiasmo, pero no trabaja en su interior hasta muy tarde: el cubismo prácticamente ignora unas investigaciones, paralelas y complementarias a las suyas, que el cine estaba emprendiendo en torno al tiempo y al perspectivismo; el futurismo prefiere, hasta muy tarde, la máquina decimonónica a la máquina de discurso que era el cinematógrafo; el expresionismo, por su parte, sólo dio algunos frutos después de 1920 y amparándose en estructuras narrativas de neto sabor romántico, aunque decoradas con un vago estilo expresionista (SánchezBiosca, 1990). 
ridad, se desplaza al cine, más apto para producir efectos de shock. en un período similar, S.M. Eisenstein inicia sus experimentos sobre la atracción en el seno del Proletkult teatral para, en 1924, desembocar en la imagen fílmica, idónea, en su opinión, para golpear la sensibilidad del espectador de acuerdo con los principios reflexológicos paulovianos con los que el autor trabajaba en la época ${ }^{10}$. No es ahora pertinente constatar las notables diferencias que separan estas dos concepciones de la materia teatral y fílmica, pues ya fue señalado tiempo atrás por Montani (1971), sino de subrayar su semejanza al calor de la teoría del extrañamiento. Así pues, Sklovski insiste en establecer un parangón entre el funcionamiento poético (extrañamiento sistemático) y la aparición de series asociativas que rompen con el desarrollo causal de la obra y, por tanto, subraya en el montaje de las atracciones eisensteiniano la presencia del eje metafórico que él mismo había postulado para el extrañamiento.

Dejemos de lado por el momento el montaje de atracciones y abordemos las concepciones excéntricas de la FEKS, uno de los grupos de la vanguardia teatral y cinematográfica soviética que dieron el salto en 1922, tras el período del comunismo de guerra, a la palestra artística. Dos rasgos advierte en seguida el lector de sus manifiestos: por una parte, la fascinación maquinística que arrancó del futurismo aparece aquí investida de un desaforado americanismo; por otra, una tendencia centrífuga en el texto, inspirada en espectáculos menores, que parece el eco, demasiado visible para ser casual, de las teorizaciones de los formalistas rusos en torno a la ostranenie. Respecto al primer aspecto, estos autores leen, por así decir, la entera vida norteamericana como una manifestación de lo mecánico reductible a la idea de montaje, cuya expresión última habría de ser la moderna cultura de masas. Pero interpretan la estructura formal del maquinismo como un fenómeno de extrañamiento, lo que les lleva a identificar principio formal y rasgo de modernidad. La mera cita de algunos fragmentos ayuda a esclarecer la convergencia entre ostranenie y maquinismo, como se revela en el temprano «Manifiesto del Excentrismo», que data de 1922 y fue firmado por Grigori Mijailovitch Kozintsev, Georgy Krizicky, Leonid Zacharovitch Trauberg y Serguei Josifovitch Yutkevitch. Reza así:

10 En otro lugar (Sánchez-Biosca, 1991) hemos tenido ocasión de detallar in extenso lo que resulta imperceptible a la sensibilidad excéntrica de Sklovski y separa radicalmente a Eisenstein de la actitud de la FEKS. Se trata de dos concepciones del montaje opuestas incluso, pero que arrancan de este frente común que constituye nuestro objeto de interrogación hoy. 
«1) AYER: estudios cómodos. Frentes despejadas.

Razonaban, decidían, pensaban.

HOY: la Señal. ¡A las máquinas! Correas, cadenas, ruedas, manos, pies electricidad.

El ritmo de la producción.

AYER: museos, templos, bibliotecas.

HOY: fábricas, talleres, astilleros.

2) AYER: la cultura de Europa.

HOY: la técnica de Norteamérica.

$\mathrm{La}$ industria, la producción bajo la bandera estrellada. $\mathrm{O}$ americanización, o a la funeraria.

3) AYER: salones. Reverencias. Barones.

HOY: Gritos de vendedores callejeros, escándalos, la porra

del policía, ruido, gritos,

pateo, carrera.

Ritmo de hoy:

El ritmo de la máquina, concentrado por Norteamérica, introducido en la vida del boulevard» (Kozintsev et al., 1978:33).

Acaso no sea difícil percibir en esta descripción cómo la vida norteamericana urbana y moderna aparece mitificada a través del prisma de la industrialización, del ritmo frenético callejero y de su emblema -la fábrica-; pero además, todo ello es interpretado a la luz de rasgo formal, a saber, el excentrismo. Puede sorprender que un movimiento de vanguardia como la FEKS mantuviera en el momento álgido del ímpetu soviético un ideal tan contradictorio con los destinos colectivistas en los que se iba a aventurar el arte soviético. Lo cierto es que el principio formal se impone sobre el destino militante y este rasgo de 'izquierdismo' les sería criticado desde las altas instancias del PCUS. Para la FEKS, el arte debe comportarse de acuerdo con el ritmo trepidante de la vida moderna e imitar su estilo. Con todo, la fábrica, si bien lo pensamos, dispone de un símbolo de productividad que se convertiría en mito enel desarrollismo soviético: la cadena de montaje. Y es ahí donde hallamos la confirmación del campo semántico en que se mueve nuestro concepto: aquí aparece aludido el único elemento de nuestra constelación que Sklovski no había nombrado ni pensado, la técnica. Ahora bien, el mito maquinístico, urbano y americanista, ha dado su fruto discursivo en la medida misma en que ha encontrado a su paso un instrumento formal de comportamiento textual: el extrañamiento. La mezcla entre el texto artístico y la producción del objeto material, la violencia espectacular, el recurso al truco sorpresivo, la mezcla indiscriminada de estilos, la función modelizadora de la máquina fabril, la interpolación del circo y la feria consideradas como atracciones, el culto al frenesí del ritmo... son éstos los elementos fundamentales que designan un modelo de arte cuya génesis hay que ver en este principio ubicuo del montaje: 
«1) Espectáculo: golpes rítmicos en los nervios.

2) Cumbre: el truco.

3) Autor: inventor + inventor.

4) Actor: movimiento mecanizado, con patines de ruedasen lugar de coturnos, una nariz que se enciende enlugar de máscara. Interpretación: en lugar de movimiento, bufonería; en lugar de mímica, mueca; enlugar de palabra, grito.

Nos gusta más el culo de Charlot

que las manos de Eleonora Duse!

5) Pièce: acumulación de trucos: Ritmo: 1000 caballosde vapor. Carreras, persecuciones, fugas. Forma: eldivertissement.

6) Jorobas que crecen, barrigas que se hinchan,pelucas de clown que se elevan: principio de un nuevo vestuario escénico. Fundamento: una incesantetransformación.

7) Sirenas, disparos, máquinas de escribir, silbidos; la música excéntrica, tip-tap: inicio de un ritmo nuevo.

Nos gusta mucho más las suelas dobles del bailarín americano que los quinientos instrumentos del teatro Marynsky.

8) Síntesis de los movimientos: acrobático, deportivo, danzante, constructivamente-mecánico.

9) Can-cán en la cuerda de la lógica y del buen sentido. De lo 'inimaginable' y de lo 'imposible' al excentrismo.

10) De lo fantástico a la habilidad manual. De Hoffmann a Fregoli. Lo infernal norteamericano: Losmisterios de Nueva York, La máscara que ríe.

11) Dar la mano al Vseobuc. El deporte en el teatro. Las medallas del campeón y los guantes del boxeador. ¡Parade allez!, más teatral que las muecas de Arlequín.

12) Empleo de los procedimientos de la propaganda norteamericana.

13) Culto del parque de atracciones, de la gran noria y de las montañas rusas. Las sonoras bofetadas del payaso. Poética: 'El tiempo es dinero!'» (Kozintsev et al., 1978:34-35).

La vida americana es contemplada a la luz de sus imágenes más llamativas, aquéllas que dieron la vuelta al mundo y que proceden de sus filmes cómicos, sus slapsticks; expresión de ritmo trepidante que fascinó a los vanguardistas soviéticos hasta límites insospechados. Un dato significativo confirma esta sospecha: Grigori Kozintsev propone una lectura del 'gag' propio del slapstick utilizando todos y cada uno de estos criterios y reconociendo en él la más pura expresión tanto del montaje como de la vida moderna que debe ser imitada por el arte. En efecto, para este cineasta, el procedimiento del 'gag' debe ser entendido como una transposición de elementos, como una confusión entre causa y efecto, una distorsión semántica. La metáfora se torna realidad o, lo que para él es equivalente, la realidad se convierte en metáfora. Pues bien, su razonamiento concluye con la afirmación de que el gag es, al igual que el excentrismo, una puesta al desnudo del recurso que ha servido para la composición: el humorismo nace, pues, de la relación entre los elementos y no de los elementos considerados de modo aislado. Procediendo a unir aquello que no puede estar unido, aquello 
que contradice la lógica, el 'gag' entra a formar parte del disparate (Kozintsev, 1973:90). Como puede verse, la argumentación de Kozintsev concluye con una definición que evoca una vez más la ostranenie de Sklovski. Poco importa si ello fue voluntario; lo cierto es que revela hasta qué punto la lectura excéntrica se aplica por doquier a textos propios y ajenos en estos fructíferos años de vanguardia. Muy poco tiempo después, S.M. Eisenstein emprendía una lectura sistemática en clave de montaje de textos clásicos, entre los que no faltaron autores como El Greco o Góngora (sic!). Y quizá cabría considerar en este mismo contexto la sensibilidad hacia el montaje que ponían de manifiesto Pound y Fenollosa (1977) al estudiar el carácter de la escritura china como medio poético. Era claro que una actitud nueva, que ponía el acento en la heterogeneidad y el montaje, había encontrado en la ostranenie un síntoma y una herramienta idóneos a través de los cuales expresarse. Claro que el síntoma — bien lo sabemos- no encarna la totalidad, sino que se limita aludirla metonímicamente.

\section{TINIANOV, GUIONISTA DE LA FEKS}

Pronto la FEKS trasvasaría estos principios generales del teatro al cine. Fue en 1924 con Las aventuras de Octobrina, comedia en tres actos realizada por Trauberg y Kozontsev. Sin estructura, el fiome se reducía a un conjunto de trucos, sobreimpresiones y mecanismos extraídos del slapstick americano, donde no faltaron procedimientos característicos de la cultura de masas. Resulta harto significativo el hecho de que, para evaluar la poética cinematográfica de la FEKS, Vladimir Nedobrovo recurra en 1928 a una explícita terminología formalista, introduciendo por enésima vez el concepto de ostranenie: «El sentido del método excéntrico de la FEKS - es necesario decirloconsiste en arrancar los objetos y las ideas de su proceso automático. La FEKS procura dar la sensación del objeto a través de una visión, y ya no a través de un reconocimiento. Su procedimiento excéntrico es un procedimiento de complicación de la forma. La complicación de la forma prolonga la percepción del objeto en el plano temporal e implica a la totalidad del proceso perceptivo» (Nedobrovo 1978:90). En este contexto de recurrencias, nada sorprendente es la explícita colaboración que unió al grupo capitaneado por Grigori Kozintsev y Leonid Trauberg con algunos de los autores de la escuela del método formal. El dato más llamativo, pero en absoluto el único, es la puesta en esce- 
na para el cine por Trauberg y Kozintsev de El Capote (Shinel), 'a la manera de Gogol', en 1926 y según guión del formalista Yuri Tinianov, quien se basó en dos cuentos, «El Capote» y «La perspectiva Nevski», ambos de Gogol. Llama poderosamente la atención la muy libre elaboración del guión por Tinianov y, sobre todo, el hecho de que se inspirara en la interpretación de El Capote hecha por Boris Eichenbaum en 1918 en un artículo que llevaba por título «Cómo está escrito El Capote de Gogol».

En dicho texto, Eichenbaum sostenía que el argumento de la narración de Gogol sólo servía para ligar procedimientos estilísticos particulares y apuntaba la existencia de palabras situadas fuera del sentido: «dichas palabras son apenas perceptibles como unidades lógicas, como designaciones de nociones; descompuestas y recompuestas según el principio del discurso fónico. Este es uno de los efectos de la lengua de Gogol» (Eichenbaum, 1966: 167). Desacuerdo cómico entre la tensión de la entonación sintáctica y su consistencia semántica, cambios de tono, interrupción, surgimiento de lo grotesco para cuya explicación recurre Eichenbaum al teatro: «Este procedimiento recuerda el recurso escénico que consiste en que el actor sale de su papel y se dirige directamente a los espectadores» (Eichenbaum, 1966: 171). De ahí la insistencia en el artificio; término, como se sabe, de sabor sklovskiano. En suma, el procedimiento que Eichenbaum advierte en Gogol consiste en «concicliar lo inconciliable, exagerar lo insignificante y minimizar lo importante, habiendo previamente aislado de la vasta realidad el mundo del relato» (Eichenbaum, 1966: 173). Ya nos encontramos muy próximos de la idea de montaje y el hecho de que Eichenbaum recurra a símiles cinematográficos como el de primer plano para definir la actitud ante los detalles de Gogol no puede considerase ocioso.

Pues bien, Shinel (El Capote) como filme combinó los dos cuentos de Gogol indicados, procurando ser fiel a la noción de lo grotesco enunciada por Eichenbaum, eliminado los elementos más realistas y desarrollando el aspecto de estilización, tanto en la invención de escenas nuevas, como en el uso de una atmósfera irreal basada en decorados deformados o procedimientos de cámara, iluminación e interpretación. Esto sugiere que el responsable de la relectura no fue tan sólo Tinianov, sino que en ella colaboran Trauberg, Kozintsev y el operador Andrei Moskvin. Tanto es así que por la interpretación grotesca de su actor principal, quien se movía cual marioneta según el modelo expresionista, por los trucajes de cámara (sobreimpresiones, filtros, desenfoques, etc) y por el tratamiento deformado de la escenografía, Shinel fue considerada una película experimental (Zorkaja, 1989:86) y logró 
muy pronto fama de película formalista, entendiendo por tal su concomitancia con los planteamientos de la escuela de la OPOJAZ (Lebe$\operatorname{dev}$ 1962: 264).

Valga añadir que el caso no fue aislado y las colaboraciones de los formalistas se multiplicaron: Sklovski trabajó en una treintena de películas (entre ellas Por la ley, de Lev Kuleshov, 1926, basado en el relato de Joack London «The Unexpected») con autores de la talla de Boris Barnet, Olga Preobrajenskaia, Abraham Room, etc, mientras Ossip Brik, por su parte, colaboró con Pudovkin y Kuleshov y el mismo Tinianov fue guionista junto a Julian Oksman del film S.V.D., dirigido por Trauberg y Kozintsev en 1927.

\section{POETIKA KINO}

Es este el título del volumen colectivo que los formalistas rusos consagraron en 1927 al estudio del cine. Poetika Kino (Eagle, 1981) constituye una reflexión de conjunto sobre el discurso cinematográfico, especialmente en las aportaciones más globalizadoras de Yuri Tinianov y Boris Eichenbaum y se presenta aún hoy como la primera sistematización teórica alejada de la práctica fílmica (frente a las teorías llamadas formativas de las primeras décadas) y concebida en el período de la elaboración de las teorías del montaje y la forma fílmica de Lev Kuleshov (1974) y V. Pudovkin (1949).

Tal y como los autores del método formal plantean, el cine no debe ser analizado en relación con realidad ninguna, sino en cuanto material construido por procedimientos característicos de un sistema significante. No obstante, una afirmación semejante podría ser suscrita por los teóricos formativos, por los enseñantes y experimentadores soviéticos del período o, incluso, por la mayor parte de los teóricos de la vanguardia que dirigieron su mirada hacia el cinematógrafo en alguna ocasión. ¿Dónde hallar, pues, la especificidad de la contribución de Poetika Kino?

Uno de los teóricos formativos, Louis Delluc, se había referido a la 'fotogenia' para describir la cualidad específica del cinematógrafo. Eichenbaum recoge el término y lo transforma sustancialmente privándolo de su resabio esencialista y otorgándole una condición semiótica, al afirmar que la fotogenia no se refiere a los objetos ni a las per- 
sonas de la vida real, sino a cómo están transmitidos cinematográficamente, es decir, por medio de qué procedimientos formales, angulaciones de cámara, puntos de vista, etc son tratados (Eichenbaum, 1981:57). Puede, mediante este dato concreto, advertirse la distancia que separa a Eichenbaum de autores como Delluc o Abel Gance Gance y, por extensión, de Germaine Dulac o Jean Epstein al tiempo que servir de botón de muestra de la revolución teórica formalista: allí donde los teóricos formativos apelan a una cualidad supuestamente congénita del cine, los formalistas se fijan en el tratamiento específico del procedimiento o procedimientos con los que está construido el discurso. En consecuencia, el cine ya no puede ser definido por rasgos metafóricos tales como 'música de los ojos' o 'poesía visual', muy frecuentes al filo de 1920, sino que exige una concepción más rigurosamente estética y lingüística.

Ahora bien, si el estudio del cine no puede ser agotado refiriéndose a la realidad, ni tampoco resulta adecuado definirlo por sus semejanzas con las otras artes, ello se debe precisamente al carácter arbitrario de sus signos. Esto lleva a Tinianov, a postular que el cine es, en realidad, un arte abstracto, cuyo valor sígnico es inversamente proporcional a su capacidad referencial. En efecto, la cualidad planaria de la imagen, es decir, su bidimensionalidad, la restricción cromática del blanco y negro, la carencia de sonido y diálogos y las limitaciones del punto de vista constituyen a un mismo tiempo la 'pobreza realista del cine' y su riqueza discursiva (Tinianov, 1981: 81). Dicho en otros términos, son las limitaciones realistas las que convierten la imagen en un signo. Así pues, el mundo visible se presenta en el cine -esta definición es quizá la más célebre de cuantas pronunciaron los formalistasen su correlación semántica. Y esta noción de correlación semántica nos conduce inexorablemente al montaje.

Tinianov considera que el montaje no consiste en la mera unión de imágenes, sino en su sucesión diferencial y ésta puede producirse en tanto en cuanto dichas impágenes tienen un punto de correlación. Repetición y diferencia son, por tanto, los ejes sobre los que actúa el principio semiótico del montaje. Y éste aparece, entonces, en el corazón de la sucesión discursiva del cine. Dicho en palabras de Eichenbaum, el montaje es el sistema que construye la sintaxis fílmica. Y aquí se bifurcan los caminos: por su parte, Tinianov busca el modelo del cine en la poesía, considerando que el ritmo es el 'factor constructivo del verso', como definió en su libro El problema de la lengua poética. Relacionado con la poesía y el ritmo, el montaje aparecerá como la interacción de movimientos estilísticos y métricos en el desarrollo del 
filme. Por su parte, Eichenbaum concibe el cine, gracias al montaje, como un arte de la sucesión y, por tanto, su modelo debe buscarse en la prosa. El montaje se transforma en la estilística fílmica en la medida en que garantiza todas las formas de articulación de las unidades sígnicas. Eichenbaum hablará de los film-períodos, basados en la construcción de contigüidades espaciales y temporales que producen ilusión de continuidad espaciotemporal. Todo el sistema de articulaciones que va de la cine-frase a la cine-oración, objeto de estudio de la cine-estilística, tiene su instrumento decisivo en el montaje. Al cabo de este razonamiento, podemos comprender con mayor claridad la siguiente expresión de Eichenbaum: «El cine posee su propio lenguaje, su propia estilística y sus propios procedimientos de fraseo. Uso estos términos, por supuesto no para aproximar el cine al arte verbal, sino en el sentido de una legítima analogía, al igual que se habla, por ejemplo, de la 'frase musical', 'sintaxis musical', etc» (Eichenbaum 1981: 68).

\section{EPÍLOGO}

Lo expuesto en estas páginas se limita a ser un recorrido de los primeros textos formalistas en su interrelación con manifiestos y prácticas vanguardistas contemporáneas. Todos ellos revelan repetidamente un lenguaje y conceptualización comunes de cuño excéntrico. Ahora bien, tales actitudes constituyen sólo una fase, necesaria pero transitoria durante la cual se hizo hincapié en el valor de cada parte autónoma, cada significante disociado del resto en el seno de los textos. No puede deberse al azar que apenas una década más tarde, el espíritu disruptivo de la vanguardia dé paso a una reflexión que se pretende científica, provista de un metalenguaje homogéneo y un espíritu constructivo. $Y$ en esta nueva época el principio de montaje dejaba su lugar a la tiranía de la construcción. El montaje se había desplazado de la práctica a la teoría y acaso el surgimiento muchas décadas más tarde de la deconstrucción no sea sino el último capítulo y la forma más contundente de teorizar una práctica que la vanguardia ejercitó por doquier ${ }^{11}$.

11 Un estudio complementario de éste es el que dedicamos, en otro texto gemelo, a la obra de Eisenstein y al proceso que media entre el montaje de atracciones y su teoría general del montaje. Introducir estas reflexiones en esta ocasión hubiera complicado sensiblemente la inteligibilidad de este escrito. 


\section{Referencias bibliográficas}

Adorno, Th.W, (1980). Teoría estética. Madrid: Taurus.

BENJAMIN, W. (1975). Tentativas sobre Brecht. Iluminaciones III. Madrid: Taurus.

Benjamin, W. (1982). Das Passagen-Werk. Franfurt: Suhrkamp.

Breton, A. (1975). Manifestes du surréalisme. Paris: Gallimard (texto de 1924).

Bürger, P. (1987). Teoría de la vanguardia. Barcelona: Península.

DE MARIA, L. (1973). Marinetti e il Futurismo. Verona: Mondadori.

DORFLES, G. (1984). "El concepto de ostranenie como fenómeno interválico». En El intervalo perdido, 97-122. Barcelona: Lumen.

Eagle, H.(1981). Formalist Film Theory. Michigan: Slavic Publications (ed. ing. Poetika Kino).

Eichenbaum, B. (1970). «La teoría del método formal». En Todorov ed., 2154 (texto de 1925).

Eichenbaum, B. (1970). «Cómo está hecho El Capote de Gogol». En Todorov ed. , 159-176 (texto de 1918).

EICHENBAUM, B. (1981). «Problems of cinema Stylistics». En Eagle ed., 58-80 (texto de 1927).

ERLICH, V. (1974). El formalismo ruso. Barcelona: Seix Barral.

Fenollosa, E. \& Pound, E. (1977). El carácter de la escritura china como medio poético. Madrid: Visor.

Francastel, P. (1975). «Destrucción de un espacio plástico». En Sociología del arte, 153-202. Madrid: Alianza.

García Berrio, A. (1973). Significado actual del formalismo ruso. Barcelona: Planeta.

JAKOBSON, R. (1981). Lingüística, poética, tiempo. Conversaciones con Krystina Pomorska. Barcelona: Crítica.

KozINTSEV, G. ( 1973). «El arte popular de charles Chaplin». En AAVV. El arte de Charles Chaplin. Buenos Aires: Nueva Visión.

Kozintsev, G. et al. (1978). «Manifiesto del Excentrismo». En Rapisarda ed., 31-48.

KRAISKI, G., ed. (1971). I formalisti russi nel cinema. Milán: Garzanti.

Kuleshov, L. (1974). «Art of the cinema». En Kuleshov on Film. Writings of Lev Kuleshov. R. Levaco, ed., 39-123. Berkeley/Los Angeles/London: University of California Press (texto de 1929).

LEBEDEv, N. (1962). Il cinema muto sovietico. Torino: Einaudi.

MENNA, F. (1977). La opción analítica en el arte moderno. Barcelona: Gustavo Gili.

Montani, P. (1971). «L'ideologie che nasce della forma. Il montaggio delle attrazioni». Bianco e Nero 7-8, 6-19.

Nedobrovo, V. (1978). «FEKS: Trauberg y Kozontsev». En Rapisarda ed., 88-137 (texto de 1928).

Pozuelo, J. M. (1988a). Teoría del lenguaje literario. Madrid: Cátedra.

Pozuelo, J. M. (1988b). Del formalismo a la neorretórica. Madrid: Taurus.

Pudovkin, V. (1949). Film Technique \& Film Acting. New York: Bonanza (textos de 1929 y 1933 respectivamente).

RaPISARDA, Giusi, ed. (1978). Cine y vanguardia en la Unión Soviética. La Fábrica del Actor Excéntrico. Barcelona: Gustavo Gili. 
SÁNCHEZ-BIOSCA, V. (1987). «El expresionismo: hacia una relectura de las vanguardias». Ideologies \& Literature II-2, 201-209.

SÁnCHEZ-BIosca, V. (1990). Sombras de Weimar. Contribución a la historia del cine alemán 1918-1933. Madrid. Verdoux.

SÁNCHEZ-BIosCA, V. (1991). Teoría del montaje cinematográfico. Valencia: Filmoteca Valenciana.

SklovSKI, V. (1970). «El arte como artificio». En Todorov ed., $55-70$ (texto de 1917).

SkLovsKi, V. (1978). «Nacimiento y vida de la FEKS». En G. Rapisarda, ed., 84-87 (texto de 1928).

SklovSKI, V. (1971). «Letteratura e cinema» En Kraiski, ed., 99-144 (texto de 1923).

Tinianov, Y. (1975). «El ritmo como factor constructivo del verso». En $E l$ problema de la lengua poética . Buenos Aires: Siglo XXI.

Tinianov, Y. (1981). «On the Foundations of Cinema». En Eagle, ed., 81-100.

Todorov, T. ed. (1970). Teoría de la literatura de los formalistas rusos. Madrid: Siglo XXI.

TzarA, T. (1972). Siete manifiestos Dadá. Barcelona: Tusquets.

VillanUEVA, D. (1991). «Pluralismo crítico y recepción literaria». Tropelías 2, 203-218.

Zorkaja, N. (1989). The Illustrated History of Soviet Cinema. New York: Hippocrene. 